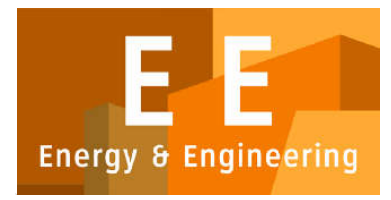

PAPER - OPEN ACCESS

\title{
Penjadwalan Mesin dengan Menggunakan Algoritma NEH pada PT. XYZ
}

\author{
Author : Ericko Wasita Rimbawan \\ DOI $\quad: 10.32734 /$ ee.v2i3.742 \\ Electronic ISSN $\quad: 2654-704 X$ \\ Print ISSN : :2654-7031
}

Volume 2 Issue 3 - 2019 TALENTA Conference Series: Energy \& Engineering (EE)

This work is licensed under a Creative Commons Attribution-NoDerivatives 4.0 International License.

Published under licence by TALENTA Publisher, Universitas Sumatera Utara 


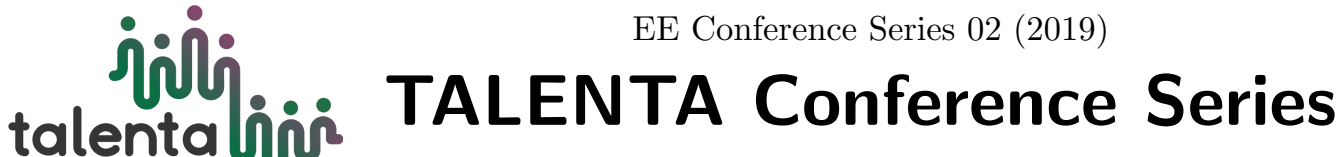

Available online at https://talentaconfseries.usu.ac.id

\section{Penjadwalan Mesin dengan Menggunakan Algoritma NEH pada PT. XYZ}

\author{
Ericko Wasita Rimbawan ${ }^{1}$ \\ ${ }^{1}$ Mahasiswa Teknik Industri Universitas Sumatera Utara, Jl. Almamater, Kampus USU, Medan, Indonesia \\ 1 erickoliee@gmail.com
}

\begin{abstract}
Abstrak
PT. XYZ adalah salah satu perusahaan baja yang ada di Sumatera Utara. Pabrik ini memproduksi baja sesuai dengan pesanan konsumen (make to order). Sistem produksi perusahaan ini adalah flow shop, dimana setiap produk melalui proses operasi yang sama. Sistem penjadwalan yang diterapkan selama ini adalah melayani pesanan yang terlebih dahulu datang (FCFS). Metode penjadwalan yang diterapkan oleh perusahaan ini masih belum optimal. Penjadwalan yang belum optimal tersebut ditandai oleh beberapa kondisi. Salah satunya adalah masih rendahnya penggunaan sumber daya yang ditunjukkan dari rendahnya kapasitas olah dibandingkan dengan kapasitas tersedia mesin tersebut. Salah satu contoh penggunaan sumber daya yang rendah adalah pada mesin rolling mill. Urutan pengerjaan job dengan pendekatan LPT adalah Job 3-Job 2-Job 1-job 4-job 5. Sementara Makespan yang dihasilkan dari penjadwalan yang diterapkan perusahaan (FCFS) adalah sebesar 3328,02 jam dengan urutan pengerjaan job yaitu Job 1-job 2-job 3- job 4-job 5. Idle time yang didapatkan dari penjadwalan menggunakan algoritma NEH pendekatan LPT yaitu sebesar 1789,91 jam (74,6 hari). Sementara idle time dari metode penjadwalan yang diterapkan perusahaan (FCFS) yaitu sebesar 3306,21 jam (137,7 hari). Efficiency Index (EI) metode penjadawalan NEH pendekatan LPT sebesar 1,09 dan Relative Error (RE) sebesar 9,87\%. Berdasarkan hasil tersebut dapat disimpulkan bahwa penjadwalan menggunakan algoritma Nawaz, Enscore, dan Ham (NEH) dengan pendekatan LPT menghasilkan makespan dan idle time yang lebih kecil dibandingkan dengan metode penjadwalan yang diterapkan oleh perusahaan (FCFS).
\end{abstract}

Kata kunci: Non-delay, simulasi, Algoritma NEH, LPT.

\begin{abstract}
PT. XYZ is a steel company in North Sumatra. This factory produces steel in accordance with consumer orders (make to order). The company's production system is a flow shop, where every product goes through the same operating process. The scheduling system that has been implemented so far is serving orders that come first (FCFS). The scheduling method applied by this company is still not optimal. The non-optimal scheduling is indicated by several conditions. One of them is the still low use of resources which is shown from the low processing capacity compared to the available capacity of the machine. One example of using a low resource is a rolling mill. The job order sequence with the LPT approach is Job 3-Job 2-Job 1-job 4-job 5. While Makespan generated from scheduling that is applied by the company (FCFS) is 3328.02 hours with a sequence of job execution namely Job 1-job 2 -job 3- job 4-job 5. Idle time obtained from scheduling using the NEH algorithm LPT approach is 1789.91 hours (74.6 days). While the idle time of the scheduling method applied by the company (FCFS) is 3306.21 hours (137.7 days). Efficiency Index (EI) NEH calendar method of LPT approach is 1.09 and Relative Error (RE) is 9.87\%. Based on these results it can be concluded that scheduling using the Nawaz, Enscore, and Ham (NEH) algorithm with the LPT approach produces smaller makespan and idle time compared to the scheduling method applied by the company (FCFS).
\end{abstract}

Keywords: Non-delay, simulasi, Algoritma NEH, LPT.

(C) 2019 The Authors. Published by TALENTA Publisher Universitas Sumatera Utara

Selection and peer-review under responsibility of The 3nd National Conference on Industrial Engineering (NCIE)

2019

p-ISSN: 2654-7031, e-ISSN: 2654-704X, DOI: 10.32734/ee.v2i3.742 


\section{Pendahuluan}

Kebutuhan baja di Indonesia, termasuk di Provinsi Sumatera Utara semakin meningkat dari tahun ke tahun. Ketatnya persaingan mengharuskan perusahaan untuk dapat memenuhi kebutuhan konsumen sebaik mungkin. Pemenuhan kebutuhan tersebut dilihat dari segi kualitas, harga, maupun ketepatan waktu pemenuhan kebutuhan konsumen tersebut.

Salah satu perusahaan baja yang ada di Sumatera Utara adalah PT. XYZ Baja yang dihasilkan oleh pabrik ini sebagian besar dialokasikan untuk memenuhi kebutuhan di Sumatera dan sebagian kecil untuk memenuhi kebutuhan baja di Pulau Jawa. Pabrik ini memproduksi baja sesuai dengan pesanan konsumen (make to order). Pesanan dari konsumen pun bervariasi, baik dari bentuk, ukuran maupun jumlah. Sistem produksi perusahaan ini adalah flow shop, dimana setiap produk melalui proses operasi yang sama.

Sistem penjadwalan yang diterapkan selama ini adalah melayani pesanan yang terlebih dahulu datang (FCFS). Metode penjadwalan yang diterapkan oleh perusahaan ini masih belum optimal. Penjadwalan yang belum optimal tersebut ditandai oleh beberapa kondisi. Salah satunya adalah masih rendahnya penggunaan sumber daya yang ditunjukkan dari rendahnya kapasitas olah dibandingkan dengan kapasitas tersedia mesin tersebut. Salah satu contoh penggunaan sumber daya yang rendah adalah pada mesin rolling mill.[1]

Algoritma Nawaz, Enscore, dan Ham (NEH) termasuk kedalam metode penjadwalan heuristik. Penjadwalan heuristik dipilih karena memenuhi kondisi-kondisi yang ada dalam produksi pembuatan baja yaitu:

1. Metode heuristik (NEH) dapat digunakan dalam masalah penjadwalan flowshop yang terdiri dari $\mathrm{n}$ buah job dan $\mathrm{m}$ buah mesin.

2. Menyebutkan bahwa algoritma NEH dapat digunakan untuk variasi produk yang tinggi.

3. Metode heuristik (NEH) digunakan untuk penjadwalan dengan ukuran performansi minimisasi makespan.

4. Algoritma NEH merupakan metode heuristik terbaik dalam penjadwalan flowshop.

\section{Metodologi Penelitian}

Metodologi penelitian menjelaskan tentang langkah-langkah penulis dalam membuat penelitian ini.

2.1 Algoritma Nawaz, Enscore, dan Ham (NEH)

Metode ini dikembangkan oleh Nawaz, Enscore, dan Ham pada Tahun 1983. Metode ini disebut sebagai metode incremental construction algorithm yang telah mendapat penghargaan sebagai metode heuristik terbaik dalam Permutation Flowshop Sequencing Problem.[2]

Adapun langkah langkah dari algoritma Nawaz, Enscore, dan Ham sebagai berikut:

1. Jumlahkan waktu proses setiap job.

2. Urutkan job-job menurut jumlah waktu prosesnya (w) dimulai dari yang terbesar hingga yang terkecil.

3. Ambil $(\mathrm{w}=2)$ dari i yang memiliki index pengurutan paling atas.

4. Buat w alternatif calon urutan parsial baru dan pilih yang memiliki makespan parsial yang terkecil, Apabila nilai makespan memiliki nilai yang sama maka ke Langkah 5. Jika tidak ke Langkah 6.

5. Dari w alternatif calon urutan parsial sebelumnyamemiliki nilai makespan yang sama, pilih yang memiliki nilai mean flow time parsial yang lebih kecil. Apabila memiliki nilai mean flow time yang sama, Maka pilihlah calon urutan parsial baru tadi secara acak.

6. Calon urutan parsial baru yang terpilih menjadi urutan parsial baru.

7. Coret job-job dari item i yang diambil tadi dari daftar pengurutan job.

8. Periksa apakah $\mathrm{w}=\mathrm{i}$ (dimana $\mathrm{i}$ adalah jumlah job item yang ada). Jika ya, lanjutkan ke Langkah 9. Jika tidak, maka ulangi ke langkah 3 dan jumlahkan $(\mathrm{w}=\mathrm{w}+1)$.

9. Urutan parsial baru menjadi urutan final.

\subsection{Metode Priority Dispatching Rule}

Priority dispatching rule adalah aturan penjadwalan yang mengatur job dimana pada suatu antrian job pada suatu mesin yang harus diproses terlebih dahulu berdasarkan prioritas-prioritas tertentu. Penelitian ini menggunakan dua pendekatan dispatching rule yaitu Shortest Processing Times (SPT) dan Longest Processing Times (LPT) [3].

1. Shortest Processing Times (SPT)

Metode Shortest Processing Time adalah metode penjadwalan yang memberikan prioritas tertinggi pada waktu penyelesaian job paling cepat diselesaikan. Adapun algoritma SPT sebagai berikut $[4,5]$ : 
a. Dimulai dengan urutan job yang tidak mengacu pada aturan SPT.

b. Alokasikan dua pekerjaan sebagai job i dan j, dimana i mengikuti j dengan syarat pi < pj.

c. Ubah urutan antara job i dan j.

d. Kembali ke langkah 2. sampai urutan SPT terbentuk.

2. Longest Processing Times (LPT)

Metode Longest Processing Time merupakan metode penjadwalan yang memberikan prioritas tertinggi pada waktu penyelesaian job paling lama diselesaikan. Adapun algoritma LPT sebagai berikut:

a. Urutkan semua tugas menurut waktu proses terpanjang (Longest Processing Time). Pekerjaan yang memiliki waktu yang terpanjang dapatkan pada urutan pertama.

b. Urutkan masing-masing tugas sesuai dengan waktu proses terpanjang pada masing-masing mesin sesuai dengan aturan waktu proses terpanjang.

c. Setelah semua tugas-tugas selesai diurutkan, balikkan urutannya pada masing-masing mesin sesuai dengan aturan waktu proses terpanjang.

\section{Hasil dan Pembahasan}

3.1. Perbandingan Penjadwalan Menggunakan Algoritma Nawaz, Enscore, dan Ham (NEH) dengan pendekatan SPT dan LPT

Berdasarkan penjadwalan yang telah dilakukan dapat dilihat perbandingan antara pendekatan Shortest Processing Time (SPT) dengan Longest Processing Time (LPT). Kedua pendekatan tersebut dibandingkan berdasarkan makespan yang dihasilkan. Perbandingan makespan tersebut dapat dilihat pada Gambar 1. berikut.

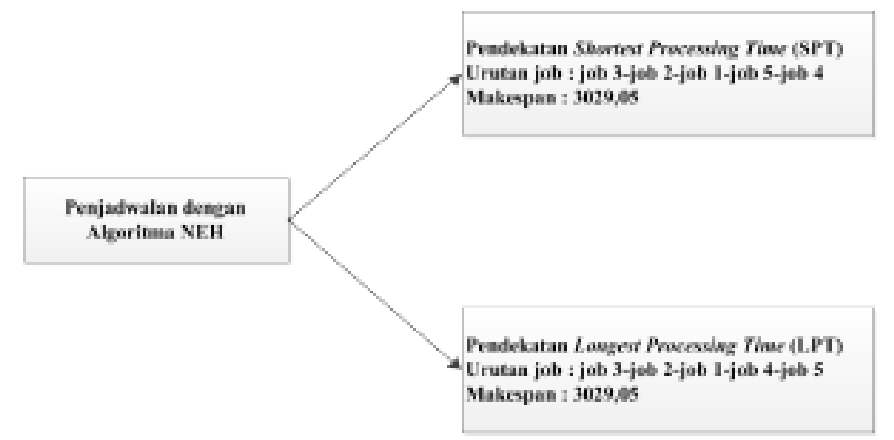

Gambar 1. Perbandingan Makespan penjadwalan NEH dengan Pendekatan SPT dan LPT

\subsection{Penjadwalan Perusahaan (First Come First Serve)}

Penjadwalan yang diterapkan oleh perusahaan saat ini adalah penjadwalan First Come First Serve (FCFS) dimana pesanan yang pertama sekali datang akan dikerjakan atau diselesaikan terlebih dahulu. makespan yang dihasilkan sebesar 3328,02. Makespan yang dihasilkan berdasarkan metode penjadwalan yang diterapkan oleh perusahan tersebut dapat dilihat pada Tabel 1.

Tabel 1. Makespan_Berdasarkan penjadwalan yang_Diterapkan Perusahaan (FCFS)

\begin{tabular}{|c|c|c|c|c|c|c|c|c|c|c|c|c|c|c|c|}
\hline \multirow{3}{*}{$\begin{array}{l}\text { Work } \\
\text { Center }\end{array}$} & \multicolumn{15}{|c|}{ Job } \\
\hline & \multicolumn{3}{|c|}{1} & \multicolumn{3}{|c|}{2} & \multicolumn{3}{|c|}{3} & \multicolumn{3}{|c|}{4} & \multicolumn{3}{|c|}{5} \\
\hline & Durasi & Mulai & Selesai & Durasi & Mulai & Selesai & Durasi & Mulai & Selesai & Durasi & Mulai & Selesai & Durasi & Mulai & Selesai \\
\hline $\mathrm{A}$ & 585.24 & 0.00 & 585.24 & 682.88 & 585.24 & 1268.12 & 780.40 & 1268.12 & 2048.51 & 76.09 & 2048.51 & 2124.60 & 97.52 & 2124.60 & 2222.12 \\
\hline B & 506.28 & 585.24 & 1091.52 & 590.71 & 1268.12 & 1858.83 & 675.03 & 2048.51 & 2723.55 & 66.04 & 2723.55 & 2789.58 & 84.57 & 2789.58 & 2874.15 \\
\hline $\mathrm{C}$ & 77.17 & 1091.52 & 1168.68 & 90.00 & 1858.83 & 1948.83 & 102.82 & 2723.55 & 2826.36 & 10.25 & 2826.36 & 2836.61 & 13.07 & 2874.15 & 2887.22 \\
\hline D & 101.66 & 1168.68 & 1270.35 & 118.50 & 1948.83 & 2067.33 & 135.32 & 2826.36 & 2961.68 & 13.87 & 2961.68 & 2975.55 & 17.57 & 2975.55 & 2993.11 \\
\hline E & 259.57 & 1270.35 & 1529.92 & 290.72 & 2067.33 & 2358.05 & 345.58 & 2961.68 & 3307.26 & 62.00 & 2975.55 & 3037.55 & 80.08 & 2993.11 & 3073.20 \\
\hline $\mathrm{F}$ & 30.38 & 1529.92 & 1560.30 & 18.20 & 2358.05 & 2376.25 & 20.76 & 3307.26 & 3328.02 & 2.25 & 3037.55 & 3039.80 & 2.81 & 3073.20 & 3076.01 \\
\hline
\end{tabular}

Perbandingan antara penjadwalan Nawaz, Enscore, dan Ham (NEH) dengan penjadwalan perusahaan yaitu First Come First Serve (FCFS) dapat dilihat pada Gambar 5.6 berikut.

\subsection{Analisa Makespan}

Berdasarkan penelitian yang dilakukan dapat dilihat perbandingan antara penjadwalan yang diterapkan oleh perusahaan yaitu FCFS dengan penjadwalan yang diusulkan yaitu penjadwalan menggumakan algoritma Nawaz, 
Enscore dan Ham (NEH) dengan pendekatan Longest Processing Time (LPT) dan Shortest Processing Time (SPT). Perbandingan keduanya dapat dilihat melalui makespan yang dihasilkan seperti pada Tabel 2. berikut.

Tabel 2. Perbandingan Penjadwalan Perusahaan dengan Penjadwalan Usulan

\section{Penjadwalan Perusahaan}

$$
\text { (FCFS) }
$$

Penjadwalan Usulan (NEH)

Job 1- Job 2- Job 3- Job 4- Job 3- Job 2- Job 1- Job 5- Job 3- Job 2- Job 1- Job 4-

\section{Urutan Job}

Makespan (Jam)
Job 5

3328,02

\section{Job 4}

3029,05
Job 5

3029,05

Perbandingan antara penjadwalan Nawaz, Enscore, dan Ham (NEH) dengan penjadwalan perusahaan yaitu First Come First Serve (FCFS) dapat dilihat pada Gambar 2. berikut.

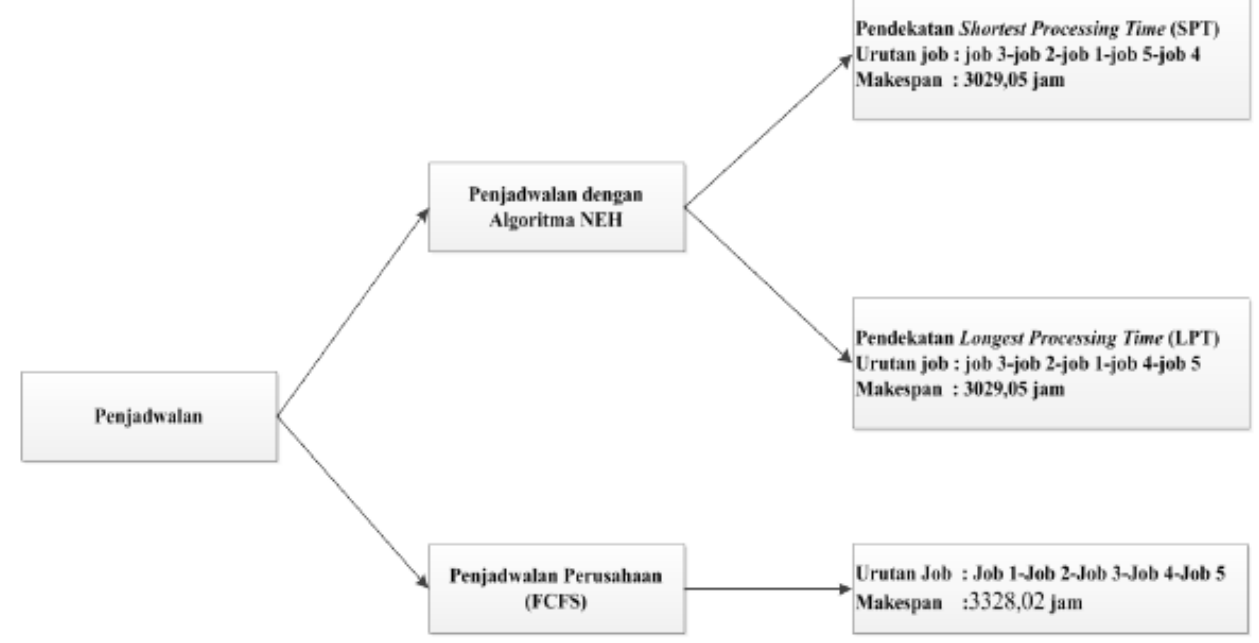

Gambar 2. Perbandingan Makespan penjadwalan NEH dengan Penjadwalan FCFS

\subsection{Analisa Idle Time}

Penjadwalan yang baik akan mengurangi idle time pada mesin karena semakin optimal sebuah penjadwalan maka waktu menganggur yang terjadi pada mesin-mesin juga akan semakin kecil. Gantt chart yang menunjukkan makespan dan idle time dapat dilihat pada Gambar 3. sampai dengan Gambar 4. Gantt chart tersebut berfungsi untuk memud

ahkan dalam melihat urutan pengerjaan job pada setiap stasiun kerja serta idle time dari masing-masing metode penjadwalan.

Gambar 3. adalah gantt chart dari penjadwalan menggunakan algoritma NEH dengan pendekatan Shortest Processing Time (SPT). Gantt chart tersebut menunjukkan pada setiap stasiun kerja urutan pengerjaan job adalah job 3-job 2- job 1-job 5-job 4. Idle time yang ditimbulkan terdapat pada work center III - work center 6. Hal tersebut terjadi karena work center tersebut menunggu proses yang belum selesai dari work center sebelumnya. Total dari seluruh idle time yang terjadi adalah sebesar 1805,62 jam (75,2 hari).

Gambar 4. adalah gantt chart dari penjadwalan menggunakan algoritma NEH dengan pendekatan Longest Processing Time (SPT). Gantt chart tersebut menunjukkan pada setiap stasiun kerja urutan pengerjaan job adalah job 3-job 2-job 1-job 4-job 5. Idle time yang ditimbulkan juga terdapat pada work center III - work center 6. Hal tersebut terjadi karena work center tersebut menunggu proses yang belum selesai dari work center sebelumnya. Total dari seluruh idle time yang terjadi adalah sebesar 1789,91 jam (74,6 hari).

Gambar 5. adalah gantt chart dari metode penjadwalan yang diterapkan oleh perusahaan yaitu First Come First Serve (FCFS). Gantt chart tersebut menunjukkan pada setiap stasiun kerja urutan pengerjaan job adalah job 1-job 2job 3-job 4-job 5. Idle time yang ditimbulkan juga terdapat pada work center II - work center VI. Hal tersebut terjadi karena work center tersebut menunggu proses yang belum selesai dari work center sebelumnya. Total dari seluruh idle time yang terjadi adalah sebesar 3306,21 jam (137,7 hari). 


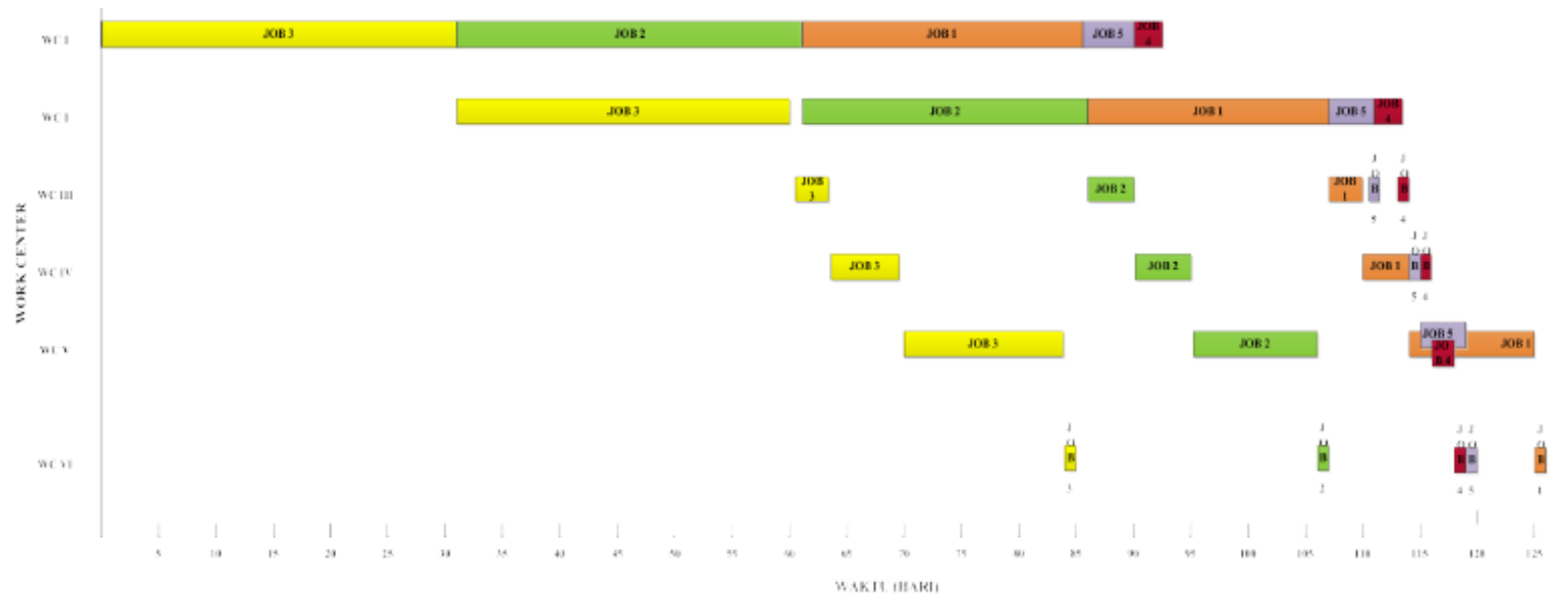

Gambar 3. Pendekatan SPT

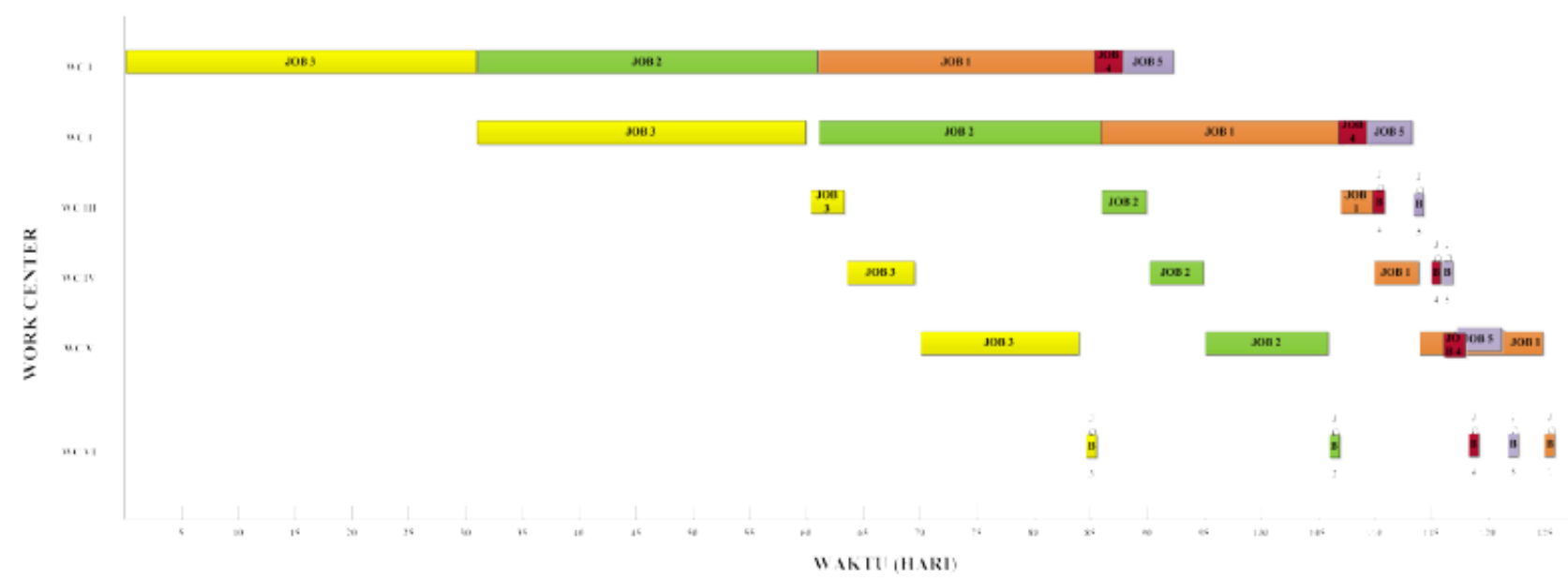

Gambar 4. Pendekatan LPT

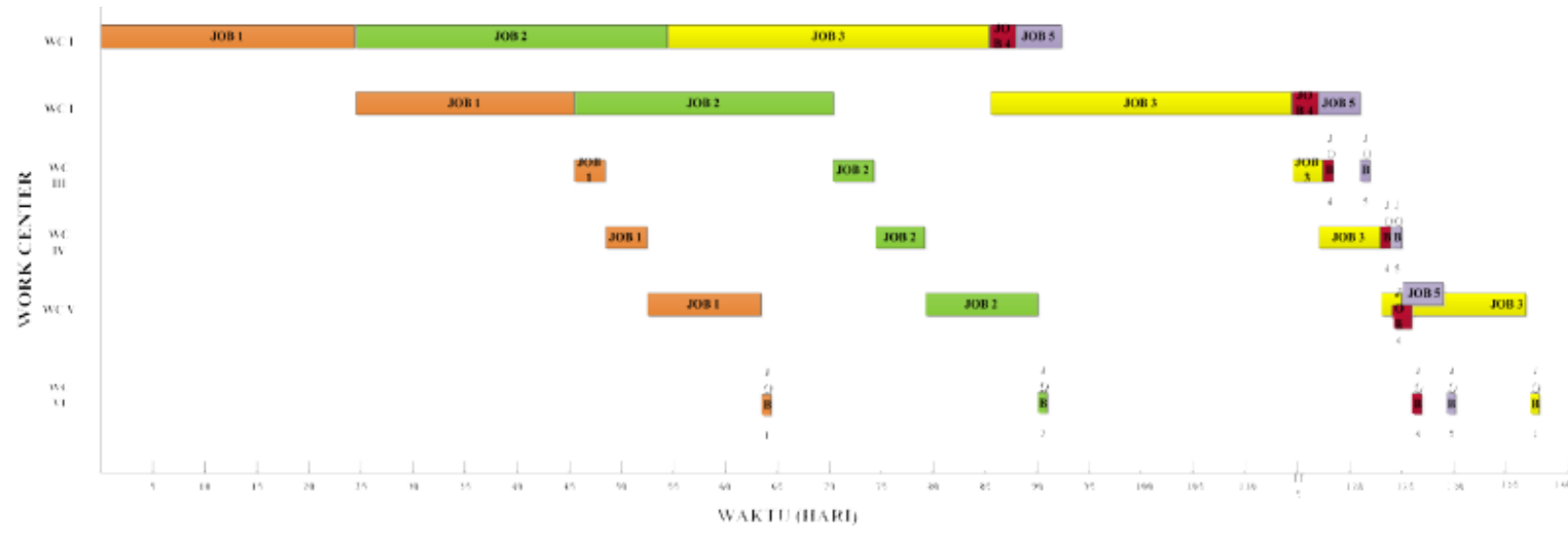

Gambar 5. Pendekatan FCFS

\section{Kesimpulan dan Saran}

Penelitian tentang penjadwalan yang dilakukan pada PT. XYZ, Ltd menghasilkan kesimpulan sebagai 
berikut.

1. Makespan minimal didapatkan dari penjadawlan menggunakan algoritma NEH dengan pendekatan SPT dan LPT yaitu sebesar 3029,05. Sementara makespan metode penjadwlan perusahaan (FCFS) yaitu sebesar 3328,02.

2. Efficiency Index (EI) metode penjadawalan NEH pendekatan LPT dan SPT sebesar 1,09 dan Relative Error (RE) sebesar $9,87 \%$.

3. Idle time minimal didapatkan dari penjadwalan menggunakan algoritma NEH pendekatan LPT yaitu sebesar 1789,91 jam/74,6 hari. Sementara idle time dari penjadwalan menggunakan algoritma NEH pendekatan SPT sebesar 1805,62 jam/75,2 hari dan dengan metode FCFS sebesar 3306,21 jam/137,7 hari.

4. Implikasi manajerial yang didapatkan dari penelitian ini adalah semakin singkatnya waktu yang dibutuhkan untuk mengerjakan keseluruhan job yang akan meminimalkan biaya operasional. Semakin rendah biaya operasional maka akan meningkatkan efisiensi perusahaan, dimana hal tersebut akan meningkatkan produktivitas perusahan.

\section{Referensi}

[1] Aryono, Columbanus, 2011, Penjadwalan N Job M Mesin Dalam Proses Pembuatan Produk Ass Mesin Jahit Dan Baut Bearing Di PT. Sinar Sakti Matra Nusantara Bandung, Bandung, Unikom.

[2] Fogarty, Blackstone, Hoffman, 1991, Production and Inventory Management, Second Edition, South Western

[3] Ginting, Rosnani, 2009, Penjadwalan Mesin, Jakarta, Graha Ilmu.

[4] Sinulingga, Sukaria. 2017. Perencanaan dan Pengendalian Produksi. Medan: Usu Press

[5] Sinulingga, Sukaria. 2008. Pengantar Teknik Industri. Yogyakarta: Graha Ilmu 